\title{
El cerebro, la lectura y el homo videns
}

\author{
The brain, the reading and the homo videns
}

Manuel Arboccó de los Heros ${ }^{1}$

\section{RESUMEN}

El siguiente ensayo presenta una serie de investigaciones, reflexiones y citas por demás interesantes sobre áreas como las neurociencias, la pedagogía y la psicología; cada una especializada en ciertas materias, pero que en algún momento se encuentran y comparten territorio, se nutren entre sí y nos ayudan a entender cada vez más el complejo mundo del conocimiento, el funcionamiento del cerebro y el comportamiento humano.

Particularmente, hoy nos preocupa el decaimiento de la palabra, de la lectura y sus posibilidades; asi como el aumento de intereses mediáticos, como la televisión tan venida a menos en las últimas tres décadas. Creemos que ciertas costumbres muy de moda en la actualidad, en vez de mejorar nuestra producción y nuestra intelectualidad, lo que generan es un empobrecimiento mental alarmante que se empieza a notar en adolescentes (inclusive universitarios) y en niños.

Iniciaremos recordando algunos descubrimientos generales del campo de las neurociencias para luego pasar al impacto de la vida postmoderna y de la tecnología mal usada en el deterioro del aparato cognitivo (y afectivo) del homo sapiens que, como diría Govanni Sartori, ya se ha vuelto un "homo videns", un ser dependiente de estímulos visuales, en detrimento del pensamiento, la abstracción y la lectura profunda.

Finalmente, también esperamos que estas reflexiones sean de interés y de impulso a otras nuevas.

\section{Palabras clave}

Neurociencias, cerebro trino, neuronas espejo, aprendizaje, lectura, salud mental, homo videns.

\begin{abstract}
The following essay introduces a number of researches, reflections, and quotes extremely relevant on areas such as neuroscience, pedagogy and psychology. Each area specializes in certain subjects but, in some moment, they meet and share common ground, nourish each other and help us understand more and more the complex world of knowledge, the functioning of the brain and the human behavior. Our concern today is the decline of the word, reading and its possibilities, as well as the increase of media interests such as the television that has deeply depreciated in the last three decades. We believe that certain trendy practices today have not contributed to improve our production and intellectuality; instead, said practices have led to an alarming mental impoverishment easy to observe in teenagers (even undergraduate students) and children.

We will start recalling some general discoveries in the field of neuroscience, then we will deal with the impact of postmodern life and technology misused in the impairment of cognitive (and affective) system of the homo sapiens, or -as Giovanni Sartori would say- the "homo videns", since it has become a dependent being of visual stimuli, to the detriment of thinking, abstraction and deep reading.
\end{abstract}

Finally, we also hope these reflections will arouse interest and boost new thoughts.

\section{Keywords}

Neuroscience, trino brain, mirror neurons, learning, reading, mental health, homo videns.

1 Psicólogo. Psicoterapeuta. Profesor de la Universidad Femenina del Sagrado Corazón y de la Universidad Inca Garcilaso de la Vega. Correo: manoloarbocco@gmail.com 


\section{El homo sapiens y las neurociencias}

Siempre se nos ha dicho que el hombre es el homo sapiens, el hombre que sabe, el hombre sabio. Olvidan, los que eso dicen, que el hombre por naturaleza (y por cronología evolutiva) primero siente, luego piensa. Es un "hombre sentidor", es emocional antes que sabio. Lo vemos tanto en la historia de la humanidad como en el desarrollo ontológico de cada ser humano. Primero se siente (miedo, alegría, cólera, dolor) y luego irán apareciendo los procesos cognitivos superiores como la imaginación, el análisis, la deducción y la razón.

Si vemos esto desde las neurociencias, campo en un feliz desarrollo, estas nos han informado de los distintos cerebros que tenemos. Paul Mac Lean (1913-2007), famoso neurólogo norteamericano, notició del cerebro triuno conformado por el cerebro reptil, que regula los elementos básicos de supervivencia; el cerebro paleomamífero, que comprende el sistema límbico y resultado de ello son las experiencias emocionales, y el cerebro neomamífero, la neocorteza que nos permite la interpretación de lo acontecido y la toma de decisiones pensadas. A diferencia de la gran mayoría de los mamíferos inferiores, el ser humano tiene los tres.

La teoría del cerebro triuno concibe la persona como un ser constituido por múltiples capacidades interconectadas y complementarias; de allí su carácter integral y holístico que permite explicar el comportamiento humano desde una perspectiva más integrada, donde el pensar, sentir y actuar se compenetran en un todo que influye en el desempeño del individuo, tanto en lo personal y laboral, como en lo profesional y social (Velásquez Burgos et al, 2006, p. 232).

Investigaciones hechas en laboratorios demuestran que las áreas cerebrales más ligadas a la humanidad y al comportamiento civilizado tienen relación directa con el lóbulo frontal, encargado del juicio, el control de impulsos y la planificación, entre otras funciones, y estas zonas aparecen activadas mayormente a medida que crecemos; por el contrario, en el niño y en el adolescente hay un predominio de zonas límbicas (LeDoux, 1999). Dato adicional, hay estudios que documentan haber encontrado que en el cerebro de asesinos en serie y en esquizofrénicos hay daños en zonas frontales y prefrontales (Gil Verona, 2002).

El hecho de crecer, aprender, socializar y madurar guarda una relación con el buen desempeño cerebral y en especial con las zonas del neocórtex. Asimismo, se está investigando cómo la violencia verbal y psicológica estarían retrasando el desarrollo normal de nuestro cerebro durante la infancia (MesaGresa, 2011). Tiene mucho sentido, ya que infantes y niños así lastimados tienen luego dificultades para el autocontrol, el aprendizaje y el equilibrio emocional. Las neurociencias dan luz en el interesante y complejo mundo psicológico.

Sigamos viendo algunas diferencias entre los cerebros de hombres y mujeres.

\section{El cerebro masculino y el cerebro femenino}

Los estudios científicos han venido dando algo de luz en el complicado mundo de los sexos y las relaciones de género. Intentar explicar ciertas diferencias entre hombres y mujeres ha sido la tarea de psicólogos, sociólogos, antropólogos, así como sexólogos y ahora neurocientíficos (Ledoux, 1999; Iacoboni, 2009).

Vemos cómo existen marcadas predisposiciones mentales y conductuales según el género. Así, por ejemplo, la hiperactividad infantil y la afasia (dificultades con el lenguaje) se dan más en niños que en niñas; la depresión por su parte, mayormente la padecen las mujeres; la esquizofrenia, el autismo y el trastorno de personalidad psicopático se dan más en varones (Aamodt y Wang, 2008; Bragdon y Gamon, 2005). ¿Por qué ocurren situaciones como las mencionadas? La ciencia y en especial las neurociencias están brindando respuestas por lo demás interesantes. Respuestas que no descartan (y muchas veces se complementan) otras de tipo familiar, sociocultural (aprendizaje, trato, costumbres). 
Hace algunas décadas, se comprobó que el cuerpo calloso (región que une ambos hemisferios cerebrales) es más grueso y más grande en las mujeres que en los hombres. Se descubrió que las mujeres emplean ambos hemisferios para casi todo y que el cerebro del hombre produce testosterona desde que está en el vientre de la madre, esto es, desde que es un feto. Además, el hipotálamo tiene casi el doble del tamaño en hombres que en mujeres.

Siguiendo con estas tendencias, observamos que la emocionalidad y la organización suelen ser femeninas, mientras que la violencia y la corrupción son mayormente masculinas. Las mujeres tienen mejor memoria emocional mientras que los hombres salen mejor en pruebas de razonamiento matemático y tareas mecánico-espaciales. El hombre está más capacitado para la concentración en una sola tarea a la vez, por su parte la mujer puede realizar más tareas simultáneamente. El tema es largo, pero estos son solo algunos ejemplos (Ledoux, 1999; Santana Martinez, 2010; Aamodt y Wang, 2008).

No se propone con esto, como erróneamente se podría creer, que un sexo es mejor que el otro o que determinadas cualidades $\mathrm{o}$ problemas son exclusivos de ellos o de ellas. Por el contrario, conocernos mejor tanto en el aspecto mental, sexual como comportamental es de gran ayuda en el proceso de desarrollo personal y de convivencia social.

A continuación, algunas reflexiones a partir del hallazgo de las llamadas neuronas espejo.

\section{El hallazgo de las neuronas espejo}

En el año 1996, los neurocientíficos italianos Giacomo Rizzolatti, Leonardo Fogassi y Vittorio Gallese que estaban estudiando la planificación y el control motor, colocaron electrodos en el cerebro de un mono. Notaron que cuando uno de estos animales observaba a otro realizar una acción, algunas de sus neuronas (del área motora) reaccionaban. $\mathrm{Al}$ principio, cuentan que pensaron era un error de medición o un fallo en el equipo. Al verificar que todo estaba bien, se encontraron con un enorme descubrimiento científico.

Así, casi de casualidad como ocurren también muchos descubrimientos importantes, hallaron un grupo de neuronas conocidas como las neuronas espejo o neuronas especulares. Se denominan así a cierta clase de neuronas que se activan cuando un animal o una persona observa una acción realizada por un semejante. Es decir, basta observar a otro haciendo algo para que de manera similar a lo que sucede en su cerebro, en el nuestro también se activen esas neuronas implicadas. Tales neuronas habían sido observadas, en primer lugar, en primates, luego se encontraron en algunas aves y de la misma forma en los seres humanos (Iacoboni, 2009).

En estudios posteriores, se pudo constatar que las neuronas espejo no solo se activan cuando vemos a alguien realizar determinada acción, es suficiente con que lo imaginemos. Por ejemplo, cuando nos imaginamos haciendo algo como trepando un árbol. Parece que, hasta cierto punto, el cerebro no diferencia lo que es real de lo que es producto de la imaginación.

El hallazgo de las neuronas espejo permite ahora entender por qué cuando vemos a otros bostezar o reír o llorar existe una suerte de "conexión emocional" (cuando la hay) con estas personas, terminando en una especie de "contagio" que reproduce en nosotros aquellas conductas (también bostezamos, reímos y de pronto lloramos).

Este descubrimiento del campo de las neurociencias permite tener una mejor explicación evolutiva y cerebral para una serie de aspectos como el aprendizaje, la imitación, la identificación y la empatía, entre otros, tan importantes para la vida y, sobre todo, para la vida social. Es probable también que estos circuitos de neuronas no se activen o que se activen deficientemente en los psicópatas, en los esquizofrénicos, en los autistas y retrasados mentales más graves (Iacoboni, 2009; Santana Martinez, 2010). A continuación, las fotografías de los descubridores de estas neuronas. 


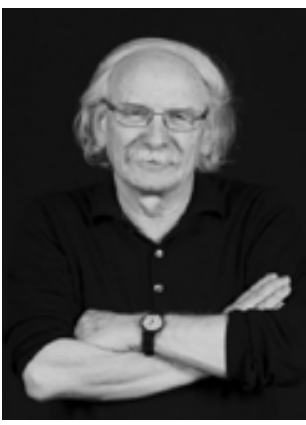

Giacomo Rizzolatti

(1937-). Imagen

tomada de: https://www. researchitaly.it/uploads/ images/rizzolatti_400.jpg
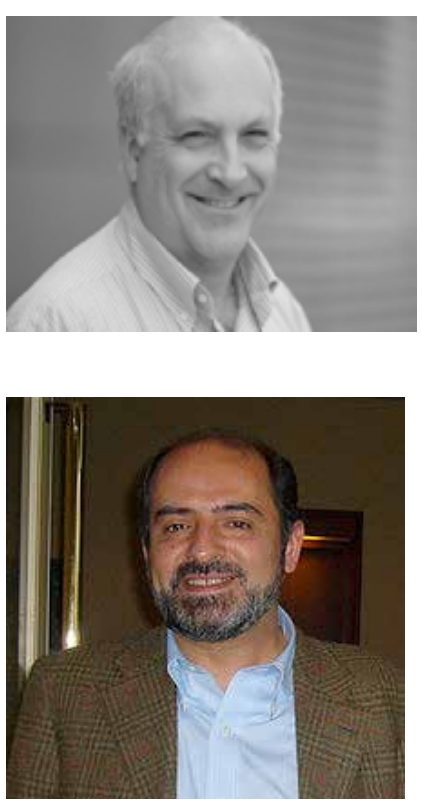

Leonardo Fogassi (1958-). Imagen tomada de: http:// www.esforum. de/photos/esf10/ p7lsm_img_1/ fullsize/Leonardo_ Fogassi_fs_fs.jpg

Vittorio Gallese (1959-). Imagen tomada de: https:// upload.wikimedia. org/wikipedia/ en/thumb/4/40/

Gallese.jpg/220pxGallese.jpg

\section{El libro y el celular}

Proponemos el siguiente ejercicio. Acérquenle a un(a) niño(a) pequeño(a) un libro y un celular y fíjense por cuál de los dos se inclina el pequeño. Lo más probable es que termine eligiendo el celular y esto no tiene nada de raro al ser un aparato que permite la interacción, tiene efectos sonoros, brinda imágenes y juegos. Es aquí donde el adulto ingresa en escena. Como adultos y personas racionales sabemos que el principal aspecto que necesita la humanidad en su proceso de formación es la palabra, el verbo, la argumentación. La lectura y luego la escritura son tareas exclusivamente humanas que nos permiten adaptarnos, socializar y solucionar muchos problemas. Y como adultos buscamos que desde pequeños, los humanos aprendan la importancia de leer y el placer de hacerlo, situación que nos permitirá acercarnos a la civilización, el entendimiento y la cultura. Pero hoy, los niños tienen desde muy temprana edad -algunos ya desde bebés- acceso al celular, la tablet y la TV y aprender a emplearlos mucho antes que a leer, y vemos que sus cerebros se están acostumbrando a no leer, con lo que puede verse limitada su imaginación, su desarrollo verbal, su capacidad de análisis y de ordenar las ideas (Sartori, 2004).

En una entrevista periodística al escritor y profesor universitario Jorge Eslava, nos recuerda que "una buena lectura es una experiencia de inteligencia e imaginación. También de sensibilidad. Creo que desarrollar la lectura desde niños cultiva y modela el espíritu" (Eslava, 2015, p.7). Por su parte, para la psicóloga y escritora Pilar González Vigil "la lectura desarrolla la imaginación de los niños, $y$ ahora se sabe, gracias a las investigaciones en el campo de las neurociencias, que nuestro cerebro no diferencia entre lo que imaginamos $y$ lo que experimentamos en la realidad. Entonces, en su mente los lectores viven la historia junto a los personajes" (González Vigil, 2015, p. 7). En estos dos comentarios, encontramos cómo formar el hábito de la lectura es fundamental en las personas, y cómo todo buen hábito debe ser formado desde pequeño. Porque el niño solo no lo hará, él se dirigirá hacia el celular (que se lo prestan siempre que lo pide) o hacia la TV (que se la encienden a toda hora) cuando de pronto tendríamos que acercarlo creativa, divertida y amorosamente al texto, al libro. La lectura (sobre todo su práctica desde pequeños) promueve el ejercicio de la atención, la imaginación, la creatividad, potencia el pensamiento abstracto y el desarrollo del lenguaje (Beltrán y Seinfeld, 2012); hay quienes ven también que la lectura nos lleva a aprender muchas otras cosas, a ser más tolerantes y nos da lecciones morales inclusive. Por su parte, el polígrafo Marco Aurelio Denegri la considera "el único vicio saludable", dice así: "Se trata, empero, de una medicina que, curiosamente, satisface un vicio; solo que un vicio saludable, el único vicio saludable: el de la lectura" (Denegri, 2011, p.70).

\section{El homo sapiens en la era del consumo exagerado}

(Desde tecnología que no necesitas hasta programas de tv que te idiotizan) 
"El peligro del

pasado era que los hombres fueran esclavos.

Pero el peligro del futuro es que los hombres se conviertan en robots"

Erich Fromm

"El mundo actual es un mundo Popeye" nos dice el psicólogo Claudio García Pintos en su texto La vida es una moneda. Así "la fuerza viene en forma de lata de cerveza, pastillas para dormir, para tener mayor vigor sexual, teléfonos de ultimísima generación y automóviles espectaculares que marcan mi nivel social, etc. Creemos ser lo que tenemos, lo que ostentamos, lo que hacemos. Compramos, consumimos, tomamos, pero la aguja sigue sin ser encontrada" (García Pintos, 2010, p. 90).

Por tanto, el hombre actual (niño o adulto) consume y consume nimiedades y ocurre algo curioso: se hace adicto a estas y ya no puede en adelante consumir menos de ellas, necesita igual o mayor cantidad para no padecer el respectivo síndrome de abstinencia y así, seguirá embotado. Se dice que nadie está obligado a dejar de hacer lo que la ley no prohíbe y como no hay ley que prohíba adormecer o embrutecer a la gente o esparcir porquería como lo hacen muchos de los medios de comunicación (sobre todo cuando la gente misma lo aprueba: léase rating) entonces el circuito nefasto continúa. En un trabajo anterior (Arboccó, M. y O'Brien, J., 2012), hemos investigado este punto. Detrás existen mezquinos intereses, monopolios, grupos de poder así como nula consciencia social. Conviene tener a la masa (de votantes, de lectores, de televidentes, de radioescuchas) adormecida, confundida, idiotizada, ignorante, y temerosa, así serán más manejables, así serán "menos peligrosos". Ya estamos viendo el bajo nivel de comprensión lectora que ostentan los muchachos hoy en día. Cierto es que este problema tiene varias causas.

Recordemos una reflexión de Mario Vargas Llosa en La civilización del espectáculo:

"La adquisición obsesiva de productos manufacturados, que mantengan activa y creciente la fabricación de mercancías, produce el fenómeno de la "reificación" o "cosificación" del individuo, entregado al consumo sistemático de objetos, muchas veces inútiles o superfluos, que las modas y la publicidad le van imponiendo, vaciando su vida interior de inquietudes sociales, espirituales o simplemente humanas, aislándolo y destruyendo su conciencia de los otros, de su clase y de sí mismo" (Vargas Llosa, 2012, p. 16).

\section{El homo videns de Sartori}

"Vivimos la cultura, de la incultura" Giovanni Sartori

En su texto Homo videns: la sociedad teledirigida (2004), el politicólogo italiano Giovanni Sartori analiza el peligro de exponer a los niños (el los llama los video-niños) ante la televisión basura y nos deja una serie de afirmaciones y estadísticas que bien puede ser tomadas en cuenta en muchas realidades sociales, las mismas que están debidamente planteadas y fundamentadas en la obra mencionada. Por ejemplo, indica que el niño ensimismado con la TV no lee; la TV modifica radicalmente y empobrece el aparato cognoscitivo del homo sapiens, el niño formado en la imagen se reduce a ser un hombre que no lee, luego ese adulto responderá solo a estímulos audiovisuales (Sartori, 2004). Además, nos recuerda que el acto de ver está atrofiando la capacidad de entender, que el hombre que lee está decayendo rápidamente $y$ lo peor de todo es que (en este mundo actual pareciera que) "ya no se necesita leer".

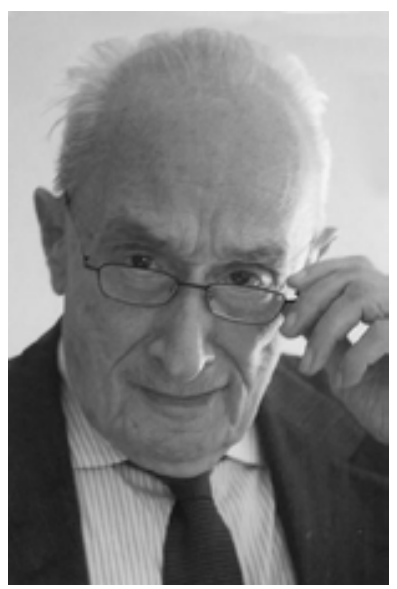

Giovanni Sartori (1924-). Imagen tomada de: http:// mlm-s1-p.mlstatic. com/homo-videns-

la-sociedad-

teledirigida-giovannisartori-pu-408001MLM20253734763 _022015-O.jpg

Sartori señala investigaciones indicando que un joven antes de terminar su adolescencia habrá 
observado horas y horas de telebasura (Sartori, 2004). Ese niño luego se transformará en un adulto empobrecido, que no lee, que responde a estímulos casi exclusivamente audiovisuales. Entre los mecanismos psicológicos de respuesta ante la telebasura están: la identificación con ciertos personajes, la imitación, la indirecta agudización de ciertos temas cuando son tratados de forma superficial y sin asesoría profesional, la asociación incorrecta de ciertos estímulos (ejemplo violencia-cotidianidad, mujer-objeto sexual, felicidad-consumismo, homosexualidad-enfermedad, amor de parejasufrimiento necesario, entre otros); también la desensibilización ante el dolor ajeno y la vulgaridad. La enorme influencia social de la tv y otros medios multiplican de forma exponencial los efectos negativos de este tipo de mensajes (Sartori, 2004).

De esta forma, vemos cómo los medios de comunicación aportan a la construcción (y destrucción) de modos de ser, de modelos de comportamientos individuales y colectivos. Nos animamos a afirmar que así se van formando modelos pobres, incultos y dependientes de las sensaciones (imágenes, sonidos) descuidando los estímulos ligados al pensamiento (la razón y la lógica). Pensamos que la lectura es una herramienta de protección contra esta época de aparatos y pantallas. Veamos eso a continuación.

\section{La lectura como un escudo protector}

"Lean lo que les apasione, será lo único que los ayudará a soportar la existencia"

Ernesto Sábato

"La lectura es un arma de resistencia ante la animalidad" Jorge Eslava

"No estás deprimido, estás distraído" nos avisaba el cantautor argentino Facundo Cabral. Y lo recordamos hace unos meses cuando visitamos una edición más de la Feria del libro de Lima. Hoy, que se habla tanto de niños y adolescentes aburridos (y adultos también), de niños y jóvenes con problemas de atención y concentración, de personas deprimidas; me preguntaba si con tanto por leer, con tantos mundos por conocer (a través de la lectura) de pronto no es que estemos tristes -como decía Cabral- sino desatentos, distraídos, mirando hacia sitios equivocados, buscando donde no hay que buscar, mirando hoy estímulos brindados por los medios que no estimulan realmente y hasta nos empobrecen cognitiva y afectivamente (Sartori, 2004).

Alguna vez oímos la frase el dolor es inevitable, el sufrimiento es opcional. Pensamos que el sufrimiento es parte de la vida, no porque la vida sea solo pesar, sino que hay situaciones inevitables, situaciones límite que tarde o temprano aparecerán. Por ejemplo, una enfermedad, la muerte de algún ser amado, separaciones, golpes climáticos, epidemias, crisis económicas y otras contingencias que involucra el estar vivo. Curiosamente la muerte, es lo que parece darle sentido a la vida. Al saberme finito y al desconocer el día de mi muerte entonces yo veo tres posibilidades: me paralizo, o me desmoralizo y me estanco o (esta es la mejor) activo mi creatividad y trato de hacer algo conmigo hoy. Hoy, porque no sabré si mañana estaré vivo. Pero hoy puedo decidir vivir, aprender algo, leer, conocer a alguien, pasear, perdonar, etc. Si yo fuera eterno, o viviera 3500 años y con plena seguridad de vivir ese tiempo, me parece que mucho -o todo- sería muy aburrido, letárgico, pero es esta finitud la que nos puede motivar a vivir mejor, a trabajar, a estudiar, a mejorar mis relaciones, a amar lo que hago, a evitar el dolor innecesario y a tomarme muchas cosas con sentido del humor.

La lectura es un pasatiempo enriquecedor que, de hacerse un hábito, consideramos puede convertirse en un escudo protector, de algunos de los males de la sociedad. Es una vacuna contra la estupidez, el aburrimiento, la chabacanería y el miedo. En este refugio, dejamos volar nuestra imaginación, potenciamos nuestra concentración, estimulamos nuestro pensamiento y nuestras capacidades lingüísticas, además de la inteligencia general y el nivel de conocimientos. Regresando al tema del sufrimiento, creemos que hay un dolor o pesar normal, necesario, sano, inclusive del que podemos aprender algo, del que podemos salir más fuertes, más dignos, más fortalecidos. (Frankl, 1991) También creo 
que hay mucho sufrimiento estéril, neurótico, estúpido, tipo telenovela. Y mucha gente no lee, pero ve telenovelas y otros programas llamados "TV basura" (Arboccó \& O'Brien, 2012).

\section{El lenguaje del Chat: Deformaciones y nuevas formaciones}

Hace un par de años, un familiar, por entonces incipiente adolescente, nos mandó un mensaje de texto vía celular y yo no lo pude leer. Fue una mezcla de sorpresa e impotencia. Despertó entonces el interés por investigar sobre este nuevo tipo de lenguaje que es el lenguaje del chat. Sorprende que no muchos se preocupen por esto: será quizá un fenómeno nuevo o difícil de abordar también. Luego oímos a algunos entendidos en el lenguaje y el manejo de los términos, así como lingüistas de carrera, que mientras este conjunto de símbolos cumpla el papel principal del lenguaje, refiriéndose al de la comunicación, todo marcha bien. Uno envía, el otro recibe, hay un código, que llega por un canal, el receptor lo comprende y responde y así hasta el infinito o la muerte o hasta que se corte el internet, que para el caso de los chicos de hoy es lo mismo.

Pero ¿̇y qué hay de las otras posibilidades del lenguaje que quedan de lado? Además de la comunicacional, el lenguaje presenta otras funciones. Karl Bühler (lingüista y filósofo alemán, 1879-1963) nos enseñó hace tiempo que existe una función expresiva (por ejemplo, "siento que esta semana que ha pasado ha sido muy provechosa") y una apelativa u operativa ("debes dejar de huir del problema y encararlo de una buena vez").

Por su parte, el lingüista y fonólogo ruso Roman Jakobson (1896-1982) nos hablaba de funciones secundarias del lenguaje, pero no por eso desestimables, como la función fática (iniciar, prolongar, interrumpir o finalizar una conversación o bien sencillamente comprobar si existe algún tipo de contacto), la función poética ("inventarte es mi forma de creerte", poema Mejor te invento de Mario Benedetti) y la función metalingüística (usar el lenguaje para hablar acerca del lenguaje, a lo Wittgenstein por ejemplo).
Es importante reflexionar que inclusive dentro de la función comunicativa el lenguaje "moderno" tampoco permite comunicarse con todos ya que es casi un dialecto entre quienes lo emplean. Es su propio gran código -aunque reducido, dicho sea de paso- con el que buscan distinguirse y alejarse. Algunas investigaciones sobre el tema indican que un jovencito peruano hoy por hoy maneja menos de 300 vocablos, cuando en el DRAE (Diccionario de la Real Academia Española) existen mucho más de 90,000 .

Pensamos que se sacrifica absurdamente estas otras funciones nobles, elaboradas, estéticas $e$ inteligentes, por emplear -ya sin esfuerzoeste minúsculo grupo de opciones. A esto se suma la enorme ayuda embrutecedora de los medios (léase radio, televisión, prensa escrita) para no necesitar esforzarse por levantar nuestro subterráneo hablar y escribir. Si dejamos de leer y dejamos también de escribir (como viene pasando), perdemos maravillosas oportunidades de desarrollo intelectual y personal.

\section{El interés masivo por la "caja boba"}

"La televisión ha hecho maravillas por mi cultura. En cuanto alguien enciende la televisión, voy a la biblioteca y me leo un buen libro"

Groucho Marx

La TV basura parecer ser el medio de entretenimiento general para la juventud ( $y$ no solo la más pobre), en un proceso que refuerza el consumismo, lo superficial y lo chabacano. Las cadenas televisivas han ido produciendo ciudadanos que muy poco saben y que se interesan por banalidades, y no son muchos los jóvenes que se percatan de esto. Vemos con pena como cientos darían la vida por ser parte de uno de estos realitys de ahora.

Entonces, dado esto, es obvio que los medios de (in)comunicación aportan a la construcción de ciertos modos de ser. Nos animamos a afirmar que así se van formando modelos superficiales, incultos y dependientes de las sensaciones descuidando los estímulos ligados al pensamiento y la razón. 
¿Qué nos ofrece esta TV actual? Historias cotidianas, las cuales son presentadas como tremendas historias de vida; mucha violencia; el desprecio por los derechos fundamentales como el honor, la dignidad o la presunción de inocencia, la idea de que lo importante es ser famoso sea como sea; la glorificación del cuerpo en desmedro de lo intelectual y lo moral, la pérdida de la intimidad y su protección, así como olvidar el comportamiento cívico y amable para con el otro ser humano.

Hoy, lamentablemente, el modelo reconocido no es el sujeto más inteligente, el más solidario o el más estudioso, por el contrario, es el más gracioso, la de mejor trasero, el más matón, la más histérica, el más escandaloso o el futbolista que tiene más dinero. Fijémonos en eso llamado "rating". Son los nuevos modelos de esta preocupante sociedad light. A estar atentos con lo que dejamos entrar a casa vía TV (Arboccó \& O'Brien, 2012).

\section{REFLEXIÓN FINAL}

\section{Leer, sobre todo leer}

En esta sociedad tecnocrática, de banalidades y chismerías, que idolatra pantallas e iguala el éxito con tener dinero o salir en la TV, es fundamental que promovamos el interés por la lectura en los más jóvenes, y este gusto por la lectura se logra en el niño pequeño cuando se le lee y en un ambiente cómodo, lúdico y afectuoso. Ese niño que se acerca positivamente al libro seguirá con él luego, ya de mayor, y estimulará constantemente su cerebro con palabras, historias e ideas.

El Plan Lector (una buena idea) debe mejorarse y potenciarse. Solo así, acercando al estudiante a la enciclopedia, al cuento, a la novela y al libro, podemos pensar que las futuras generaciones desarrollarán la interioridad, el mundo interno, hoy no estimulado por efectos mediáticos muchas veces nocivos.

Muchos padres necesitarían una consejería mínima de cómo criar a sus hijos. Una crianza que involucre el aspecto cultural desde la más tierna infancia. El papel de la lectura, el teatro, el estudio y las artes en la formación personal ya ha sido investigado, y están documentados los efectos positivos y a largo plazo que brindan en los seres humanos.

El lingüista y profesor universitario Luis Jaime Cisneros (1921-2011) decía que el único mérito que podía reclamar como propio era la lectura. Recordaba haber crecido en una casa llena de libros y cada vez que su padre le leía, párrafos del Quijote, eso era buen anticipo de los alimentos.

En las aulas, hoy vemos jóvenes con dificultades para leer, que prácticamente ya no escriben, pero son diestros en el manejo de sus pulgares, con argumentos falaces y rudimentarios a la hora de defender una posición, pegados todo el día a unos audífonos y con serias dificultades para concentrarse sin ellos y hasta para hacer algún mínimo cálculo mental. Todo esto requiere exigir a nuestro cerebro, y, si no lo habituamos desde chicos, probablemente ya de grandes será casi imposible. Si esto lo observamos en las aulas universitarias ¿qué pasará en quienes no se han insertado en el mundo académico? El maestro Jorge Luis Borges decía que, de los diversos instrumentos inventados por el hombre, el más asombroso era el libro; todos los demás eran extensiones de su cuerpo, pero solo el libro es una extensión de la imaginación y la memoria. A tenerlo en cuenta. 


\section{REFERENCIAS}

Aamodt, S. y Wang, S. (2008) Entra en tu cerebro. Barcelona: España. Ediciones B.

Arboccó, M. \& O'Brien, J. (2012) Impacto de la televisión basura en la mente y la conducta de niños y adolescentes. Avances en Psicología, UNIFÉ, Lima, Vol. 2. pp. 43-57. Disponible en versión online en: http://www.detrasdelacortina.com.pe/download/Impactotvbasura.pdf

Bragdon, A. y Gamon, D. (2005) Cerebros que funcionan un poco diferente. México. Grupo Editorial Tomo.

Dengri, M.A. (2011) Esmórgasbord. Lima: Fondo Editorial de la Universidad Inca Garcilaso de la Vega.

Eslava. J. (1 de marzo del 2015) La lectura en los niños. Entrevista del Diario El Comercio, Suplemento El Dominical, p. 6-7.

Frankl, V.E. (1991) El hombre en busca de sentido. Barcelona: Editorial Herder.

Gil Verona, J.A. y cols. (2002) Psicobiología de las conductas agresivas. En Anales de Psicología, Vol. 18, N ${ }^{\circ}$ 2, diciembre, p. 293-303. España: Servicio de Publicaciones de la Universidad de Murcia

González Vigil, P. (1 de marzo del 2015) Narrar para inspirar. Entrevista del Diario El Comercio, Suplemento El Dominical, p. 11.

Iacoboni, M. (2009) Las neuronas espejo. Madrid: Katz Editores.

LeDoux. J. (1999) El cerebro emocional. Argentinas: Editorial Planeta.

Mesa-Gresa, P. et al (2011) Neurobiología del maltrato infantil: "El ciclo de la violencia". En Rev. Neurol. 2011; 52: 489-503. España: Departamento de Psicobiología. Facultad de Psicología. Universitat de Valencia. Valencia.

Nietzsche, F. (2007) Estética y teoría de las artes. Madrid: Editorial Tecnos.

Santana Martínez, R. (2010) Neuropsicología para padres, maestros y especialistas en el área. Ensayo. Lima: Fondo Editorial de la Universidad Inca Garcilaso de la Vega.

Sartori, G. (2004) Homo videns. La sociedad teledirigida. España: Editorial Taurus.

Vargas Llosa, Mario (2012) La civilización del espectáculo. Lima: Santillana ediciones.

Velásquez Burgos, B. et al (2006) Teorías neurocientíficas del aprendizaje y su implicación en la construcción de conocimiento de los estudiantes universitarios. En Tabula Rasa, No.5: 229-245, julio-diciembre. Bogotá: Colombia. Recuperado el 30 de octubre del 2015 en http://www.scielo. org.co/pdf/tara/n5/n5a12.pdf.

Fecha de recepción: 08-02-16

Fecha de aceptación: 20-05-16 